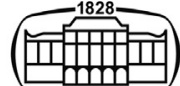

AKADÉMIAI KIADÓ

Pollack Periodica

An International Journal

for Engineering and Information Sciences

16 (2021) 2, 19-24

DOI:

$10.1556 / 606.2020 .00250$

(c) 2021 The Author(s)

\section{ORIGINAL RESEARCH}

PAPER

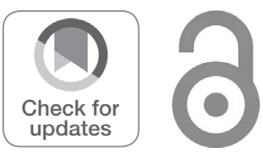

Corresponding author.

E-mail: bintulzehra687@gmail.com

\section{AKJournals}

\title{
Sustainable design of concrete using industrial additives and wastes
}

Bintul Zehra* (1), Ali Salem, Souphavanh Senesavath,
Saied Kashkash and Zoltan Orban

Structural Diagnostics and Analysis Research Group, Faculty of Engineering and Information Technology, University of Pécs, Boszorkány u. 2, H-7624 Pécs, Hungary

Received: June 2, 2020 • Revised manuscript received: September 27, 2020 • Accepted: February 16, 2021

Published online: April 21, 2021

\begin{abstract}
Concrete is the most widely used construction material in the world. Over ten billion tons of concrete are being produced each year resulting in exhaustion of natural materials and an enormous carbon footprint. One of the primary goals of concrete technology today is to reduce the use of Portland cement and natural fine aggregates by partially replacing them with various waste materials and by-products of industrial processes. The paper summarizes the results of a study where the partial replacement of river sand and Portland cement was successfully applied using steel slag aggregate, silica fume and glass waste.
\end{abstract}

\section{KEYWORDS}

sustainability, concrete, steel slag aggregate, silica fume, glass waste

\section{INTRODUCTION}

Humans have used concrete for thousands of years - its basic ingredients date back to ancient Egypt. Concrete is the most versatile and second most material used in the construction industry. Aggregates are important constituents of concrete, which occupy $70-80 \%$ of its volume. In most concrete mixes river sand acts as a fine aggregate. Nowadays due to the general shortage of river sand, it is highly important to apply substituents in concrete that are suitable for construction purposes. By using fewer good quality natural materials, the cost efficiency of the project can be maintained, and environmental aspects can also be considered. Industrial by-products and other wastes from different sources cause environmental degradation, which challenges the economic well as environmental stabilization. Moreover, it diminishes the need to dispose of this waste by giving engineering solutions with the consideration of environmental, economic and social issues. Various researchers have worked on these issues and there are numerous ongoing researches to find a better solution for the sustainable design of concrete.

Ground Granulated Blast Slag (GGBS) can be used as a cement and/or aggregate substituting material. The particle size of the GGBS that is used to replace fine aggregates is generally less than $5 \mathrm{~mm}$ [1], while the size for cement substitute can vary from 0.1 to $250 \mu \mathrm{m}$ that corresponds to the typical distribution of cement particles. It is mentioned in [2] that the size of the GGBS particles for cement substitute highly depends on the crushing time. When slag was used as an aggregate replacement in concrete it was concluded that the durability and the characteristics of steel slag cement concrete were better than those of normal concrete and it was also highlighted that there is a reduction in slump and flow values as the slag content is increased in the mixture [3].

Glass waste can be used either in a powder form, coarse aggregate or fine aggregate. It was found that using glass waste both as coarse and fine aggregates up to $50 \%$ in the concrete of 32 $\mathrm{MPa}$ strength grade showed satisfactory properties concerning strength development [4]. 
Several works have been carried out on workability, water absorption, density and compressive strength in comparison with control specimens made from conventional mixes. Test results indicated that the maximum improvement was observed at a $12 \%$ replacement rate of hill sand with a waste glass [5]. Optimal compressive strength and the splitting tensile strength of concrete were achieved when silica fume was used together with glass waste, up to $20 \%$ replacement rate. Silica fume improves the mechanical properties of concrete, including compressive, flexural and splitting tensile strengths due to the accelerated hydration of cement [6]. Junak et al. [7] studied the usage of glass waste and steel slag in concrete mixtures. They concluded that these materials could be used successfully instead of natural aggregates. It has also been concluded that steelmaking slag did not have much effect on the hardened properties of concrete and was recommended to use it in road concrete production. Glass waste with a size range of $4-8 \mathrm{~mm}$ has a compressive strength of 35 $\mathrm{MPa}$, which is close to normal concrete strength. This product is recommended for preparing good quality concrete surfaces. Martina et al. [8] studied industrial sludge. They concluded that sludge can be successfully used in self-compacting concrete as a fine particle in the range of $0-4 \mathrm{~mm}$ size.

Admixtures have a great role in changing properties when an artificial material is used in the concrete mixture. Park and Seung [9] studied the influence of super-plasticizers in concrete. They concluded that the properties of super plasticized concrete had significantly increased the workability of fresh concrete. They also reported that the use of super-plasticizer decreased the required amount of water while maintaining workability without the segregation of concrete. Hardened properties like compressive strength, tensile strength and flexural strength of concrete are increased by adding superplasticizers. Optimum super-plasticizer quantity must be used to improve concrete characteristics because overdosed superplasticizers can result in deteriorated concrete properties with decreased compressive strength and higher porosity [10].

In this work effect of glass waste and steel slag were checked by partially substitute fine aggregate, while silica fume was used as a partial replacement of ordinary Portland cement. Mixing for each concrete mix was done day wise to avoid moisture content in the mixing pan. For each concrete mix fresh concrete properties workability, the air content pressure and fresh density were evaluated altogether on the same day of mixing and later hardened strength test was done. Hardened strength properties were tested at the age of 56 days using destructive and non-destructive methods. In non-destructive method Ultrasonic Pulse velocity and Rebound Hammer test and for destructive method compressive strength was checked for each mix.

\section{MATERIALS AND PROPERTIES}

\subsection{Cement and water}

The source of CEM II/B-S $42.5 \mathrm{~N}$ was the Duna-Drava Cement Factory, Hungary. Cement was produced by fine grinding of Portland clinker, granulated blast-furnace slag 21-35\% essential properties of cement EN standard [11]. The water used in the concrete mixtures was portable, taken from the tap at room temperature. The chemical and mineralogical composition of cement is shown in Table 1.

\subsection{Fine aggregate}

The river sand was collected from the Drava River near Pécs, Hungary. River sand has a bulk density of $1,754 \mathrm{~kg} / \mathrm{m}^{3}$ and a fineness modulus of 3.8. The specific gravity was found to be 2.5. In general, all sand properties were evaluated based on the EN standards $[12,13]$. Besides, other artificial materials like steel slag and glass waste were also used to increase the sustainability of natural fine aggregate. The steel slag used in the current work was crushed and collected from Lafarge Cement, Hungary and brought from Isd Dunaferr Dunai Vasmü Ltd. Steel Plant, Hungary and was ground to achieve the desired aggregate size distribution as shown in Fig. 1. Elements present in slag are shown in Table 1. The glass waste was collected from Pécs, Hungary (Fig. 1).

The properties of natural and artificial aggregates are shown in Table 2. The morphological characteristics of natural sand and artificial sand such as grading of slag and glass waste were determined by sieve analysis. The results are shown in Fig. 2.

Table 1. Chemical composition of CEM II/B-S 42.5N, slag and glass waste

\begin{tabular}{|c|c|c|c|}
\hline \multirow[b]{2}{*}{ Chemical composition } & CEM II/B-S $42.5 \mathrm{~N}$ & Slag & Glass Waste \\
\hline & \multicolumn{3}{|c|}{ (wt\%) } \\
\hline LOI & 6.6 & -1.1 & - \\
\hline $\mathrm{CaO}$ & 59.0 & 41.4 & 10.7 \\
\hline $\mathrm{SiO}_{2}$ & 19.5 & 39.5 & 73.6 \\
\hline $\mathrm{Al}_{2} \mathrm{O}_{3}$ & 5.4 & 7.9 & 1.4 \\
\hline $\mathrm{Fe}_{2} \mathrm{O}_{3}$ & 3.3 & 0.3 & 0.5 \\
\hline $\mathrm{SO}_{3}$ & 3.0 & 0.5 & 0.1 \\
\hline $\mathrm{MgO}$ & 1.2 & 1.3 & 0.6 \\
\hline $\mathrm{K}_{2} \mathrm{O}$ & 0.6 & 0.4 & 0.4 \\
\hline $\mathrm{Na}_{2} \mathrm{O}$ & 0.2 & - & 13.1 \\
\hline $\mathrm{MnO}$ & 0.3 & - & - \\
\hline $\mathrm{TiO}_{2}$ & 0.3 & - & - \\
\hline Surface area $\left(\mathrm{cm}^{2} / \mathrm{kg}\right)$ & 3,850 & - & - \\
\hline Moisture & - & 10 & - \\
\hline
\end{tabular}

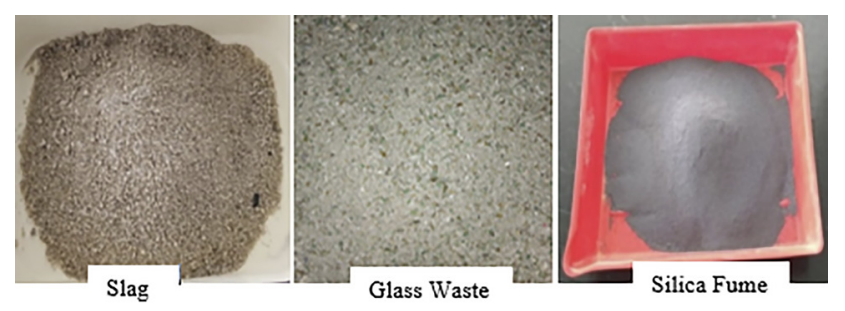

Fig. 1. Slag used; glass waste; silica fume 
Table 2. Properties of natural and artificial aggregate

\begin{tabular}{lcccc}
\hline Material & $\begin{array}{c}\text { Natural } \\
\text { sand }\end{array}$ & $\begin{array}{c}\text { Natural } \\
\text { aggregate }\end{array}$ & Slag & $\begin{array}{c}\text { Crushed } \\
\text { glass }\end{array}$ \\
\hline Particle size $[\mathrm{mm}]$ & $0-4$ & $4-16$ & $0-4$ & $0-4$ \\
$\begin{array}{l}\text { Specific density } \\
\quad\left[\mathrm{kg} / \mathrm{m}^{3}\right]\end{array}$ & 2.6 & 2.6 & 2.7 & - \\
$\begin{array}{l}\text { Fineness modulus } \\
\text { Water absorption }\end{array}$ & 3.6 & 7.9 & 4.6 & 5.5 \\
$\quad 1 \%)$ & & 0.7 & 0.9 & 0.0 \\
\hline
\end{tabular}

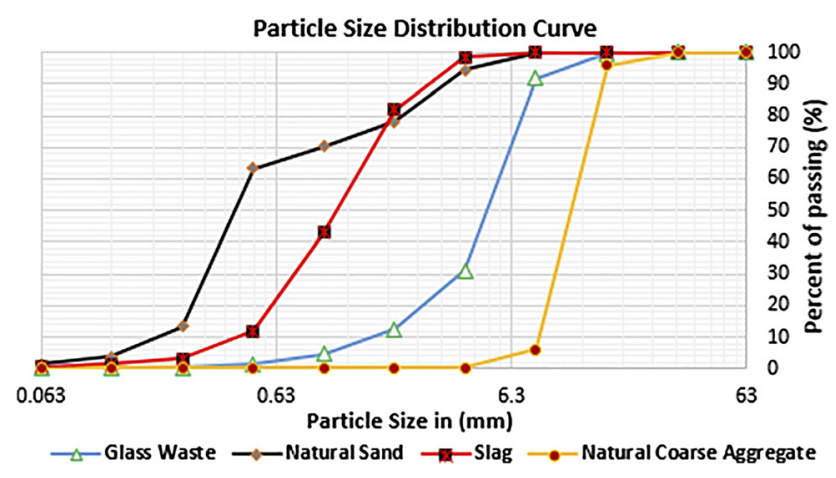

Fig. 2. The particle size distribution of glass waste, natural sand, and steel slag

\subsection{Coarse aggregate}

Following EN standard [12, 13], natural granite aggregates had a fineness modulus of 7.9 and a bulk density of $1,618 \mathrm{~kg} /$ $\mathrm{m}^{3}$. The specific gravity of coarse aggregate was 2.6. Water absorption percentage of the coarse aggregate was about $0.7 \%$. Sieve analysis results are showed in Fig. 2.

\subsection{Admixtures}

Super-plasticizer Sika Viscocrete-70 was used in the concrete mixture to adjust workability with $1.1 \mathrm{~kg} / \mathrm{L}$ density, modified polycarboxylates base, and $0.3-2 \%$ dosage by weight of cement.

\section{METHODOLOGY}

\subsection{Concrete mix design}

The concrete mix was designed following EN 1992-1-1:2004 [14]. The mix ratio was designed for oven-dried materials at a temperature of $1,100{ }^{\circ} \mathrm{C}$. The proportions of the conventional mix were as follows: cement content of $350 \mathrm{~kg} / \mathrm{m}^{3}$, a coarse aggregate of $1,098 \mathrm{~kg} / \mathrm{m}^{3}$, fine aggregate of $732 \mathrm{~kg} / \mathrm{m}^{3}$, the water content of $182 \mathrm{~kg} / \mathrm{m}^{3}$ and each specimen was added super-plasticizer Sika ViscoCrete-7710 of amount $0.875 \mathrm{~L} / \mathrm{m}^{3}$.

\subsection{Test specimens and test procedure}

For testing compressive strength of concrete tubes ultrasonic pulse velocity test, rebound hammer test and normal destructive tests were applied on the newly designed and the reference concrete specimens. Before mixing was commenced the grading of steel slag and glass waste was determined and compared to the natural aggregates. First, the experimental program consisted of testing the fresh and hardened concrete properties. Ingredients for normal and modified concrete have been thoroughly mixed until a uniform consistency has been achieved. The properties of fresh concrete were measured according to [11, 15-17].

To avoid air bubble, vibrating table is used at three successive layers, see Fig. 3. The weight of each component and the mix design proportions are presented in Table 3.

\section{RESULTS AND DISCUSSION}

\subsection{Workability}

The workability of the fresh concrete mixture was determined by slump test, according to [15]. The average slump and the corresponding air pressure content percentage are shown in Fig. 4. Results of the slump test showed that the conventional mixture provided a plastic slump with a consistent grade of S2. The slump decreased by adding silica fume, glass waste and slag replacements with a consistency grade of S1.

Usually, the cement replacement in silica fume increases workability. To verify and validate this observation the silica fume behavior in the mixture was checked separately in Mix 5 and it showed a decrease in workability, see Fig. 4. The mixture of steel slag aggregates resulted in good workability without silica fume. It was also observed that the river sand is generally finer than steel slag. The water absorption property of steel slag was higher than that of the river sand. The water-cement ratio and water-cement binder ratio were controlled by adding $0.35 \mathrm{~mL} / \mathrm{m}^{3}$ super-plasticizer. For standard constant water-cement ratio of 0.52 more water was absorbed by adding silica fume and steel slag at a higher percentage. Glass waste concrete had better workability in terms of a slump than the other concretes mixtures.

\subsection{Air content pressure}

The air content pressure in each mixture was measured according to EN 12350-7:2009 [16] and showed significant differences in air content values as shown in Fig. 4 in comparison with the slump of all mixtures.

\subsection{Density}

The values of fresh and hardened density of concrete mixtures are important aspects to define the appropriate mechanical properties of concrete. The density of fresh and hardened concrete mixtures was determined based on EN 12350-6:2009 [17] and EN 12390-7:2009 [18], respectively. Normally, the density has to be equal to or greater than $2,364 \mathrm{~kg} / \mathrm{m}^{3}$, but due to the additives, some mixtures had a density lower than the normal concrete mix 1 illustrated in Fig. 5. The mixtures with glass waste content had a very low density compared to normal concrete and the mixtures with 

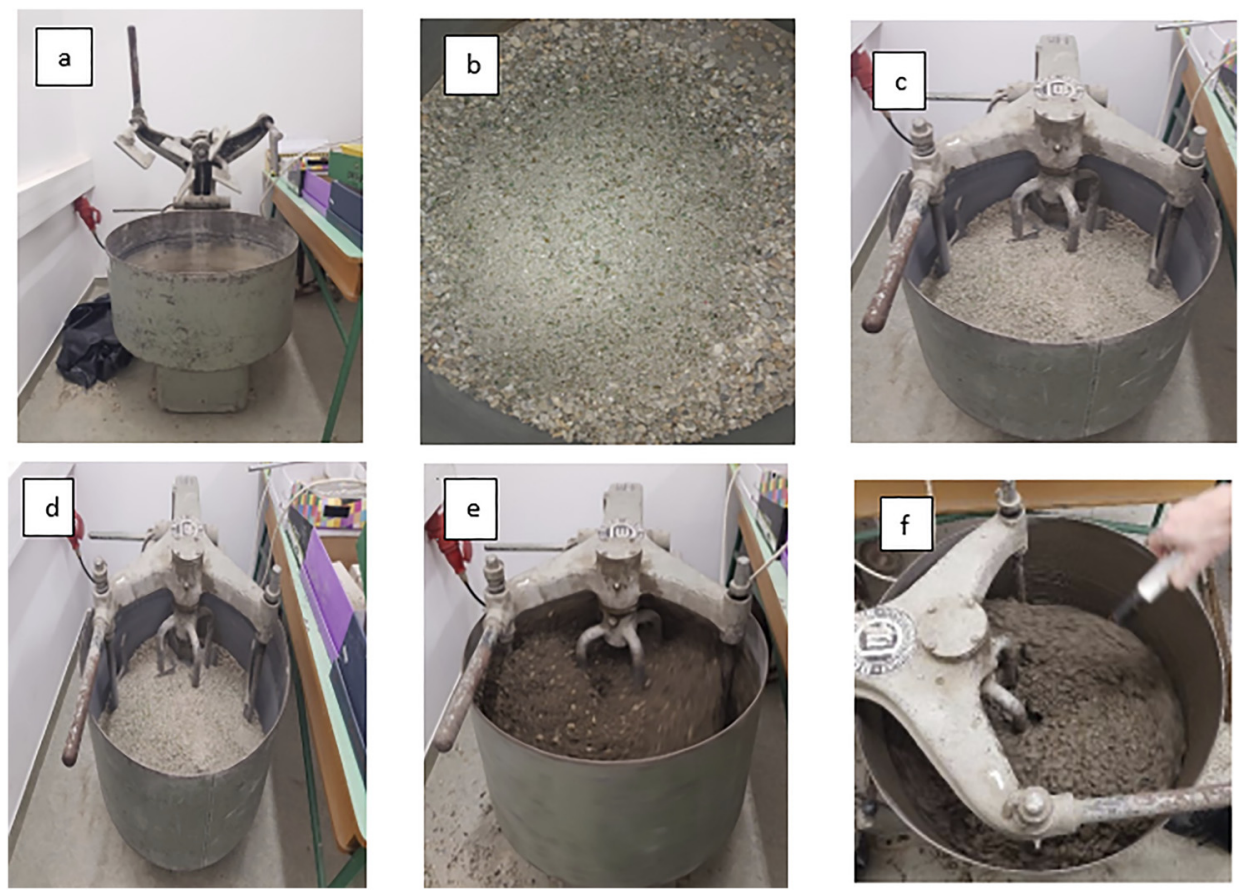

Fig. 3. Steps of concrete mixing

Table 3. Used mixture proportions

\begin{tabular}{lcccccccc}
\hline & Mix 1 & Mix 2 & Mix 3 & Mix 4 & Mix 5 & Mix 6 & Mix 7 & Mix 8 \\
\cline { 2 - 8 } Material & & \multicolumn{7}{c}{$\mathrm{kg} / \mathrm{m}^{3}$} \\
Cement & 7 & 6.3 & 6.3 & 7 & 6.3 & 7 & 7 & 7 \\
Silica fume & - & 0.7 & 0.7 & - & 0.7 & - & - & - \\
Water & 3.6 & 3.6 & 3.6 & 3.6 & 3.6 & 3.6 & 3.6 & 3.6 \\
Aggregate $(0.4 \mathrm{~mm})$ & 14.6 & 13.2 & 13.2 & 13.2 & 14.6 & 13.2 & 11.7 & 10.3 \\
Aggregate $(4-8 \mathrm{~mm})$ & 9.5 & 9.5 & 9.5 & 9.5 & 9.5 & 9.5 & 9.5 & 9.5 \\
Aggregate $(8-16 \mathrm{~mm})$ & 12.4 & 12.4 & 12.4 & 12.4 & 12.4 & 12.4 & 12.4 & 12.4 \\
Slag $(0-4 \mathrm{~mm})$ & - & - & 1.5 & - & - & 1.5 & 2.9 & 4.4 \\
Glass waste $(0-4 \mathrm{~mm})$ & - & 1.46 & - & 1.46 & - & - & - & - \\
\hline
\end{tabular}

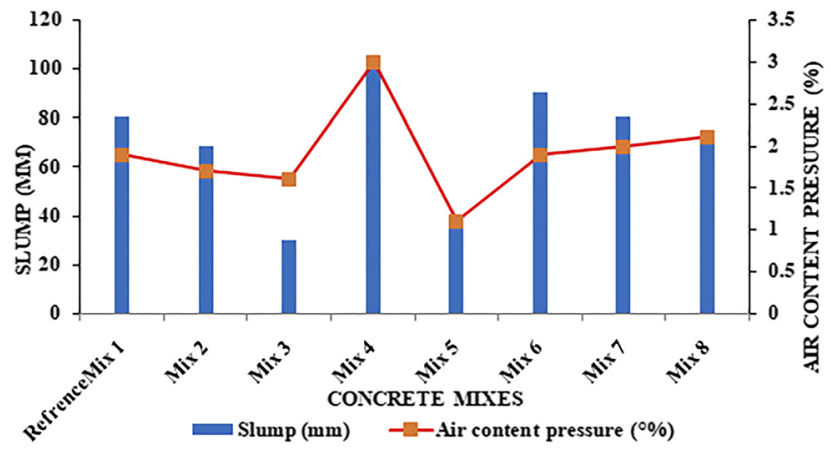

Fig. 4. Slump and air content pressure of concrete mixtures

silica fume and steel slag aggregate. The efficiency of compaction degree results of hardened concrete density compared to compressive strength is shown in Fig. 5.

\subsection{Destructive and non-destructive tests}

The ultrasonic pulse velocity and compressive strength for all mixtures were evaluated according to EN12504-4:2005 [19] and EN12390-3:2009 [20], respectively at the age of 56 days as shown in Fig. 6. The ultrasonic pulse velocity value was lower for mixes containing glass waste as fine aggregates compared to slag and convectional concrete mixes, as shown in Table 4. Results also showed that the mixes containing glass waste had acceptable strength when compared with the reference concrete mix. The estimated compressive strength is determined by combination of non-destructive methods recommended by RILEM Committee TC 43 [21].

Results of the non-destructive tests showed that the estimated compressive strength was less than the average compressive strength measured on cubes, as it is shown in Table 4. Lower values are caused by the concrete surface being softer. It was due to cured water, which resulted in reducing the energy waves. However, the mixture with $10 \%$ of glass 


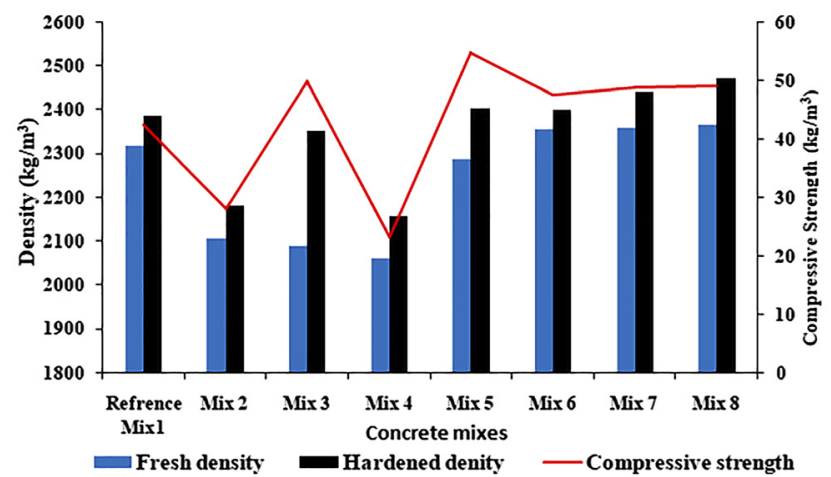

Fig. 5. Fresh density, hardened density and compressive strength values for different concrete mixes
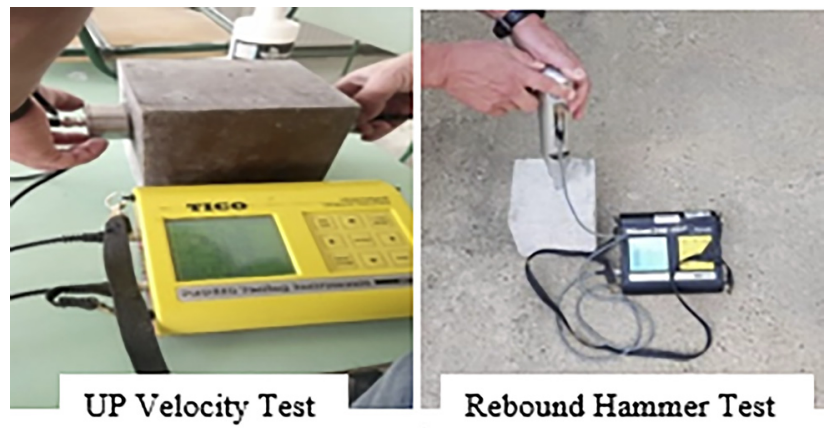

Fig. 6. Non-destructive test measurement

waste content resulted in a decreased strength. Thus, the evaluation curves for normal concrete are not directly valid for the studied concrete mixes containing specific additives.

The compressive strength of the cubes with dimensions $150 \times 150 \times 150 \mathrm{~mm}$ and average of cubes was determined according to EN 12390-3:2009 [20] tested with a Sercomp7 test machine, Fig. 7. The hardened concrete characterization for compressive strength was carried out after the age of 56 days. Results showed that the compressive strengths of the concrete mix containing glass waste and silica was lower by $34 \%$ of the reference concrete specimens. The concrete Mix 2, containing glass waste and silica fume, had higher compressive strength than that of concrete mixture No. 4, where only glass waste as fine aggregate was used. The pores in the concrete mixture decreased due to the silica fume addition.

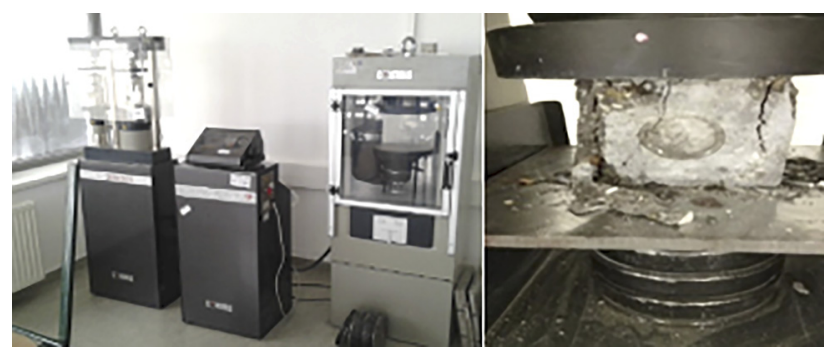

Fig. 7. Compressive strength test on cube samples
Table 4. Results of destructive and non-destructive tests of concrete

\begin{tabular}{|c|c|c|c|c|}
\hline \multirow[b]{2}{*}{ Mixtures } & \multicolumn{3}{|c|}{ Non-destructive tests } & \multirow{2}{*}{$\begin{array}{c}\begin{array}{c}\text { Destructive } \\
\text { test }\end{array} \\
\begin{array}{c}\text { Compressive } \\
\text { cube strength } \\
(\mathrm{MPa})\end{array}\end{array}$} \\
\hline & $\begin{array}{c}\text { Ultrasonic } \\
\text { pulse } \\
\text { velocity } \\
(\mathrm{km} / \mathrm{s})\end{array}$ & $\begin{array}{c}\text { Rebound } \\
\text { value, } \mathrm{R}\end{array}$ & $\begin{array}{c}\text { Estimated } \\
\text { compressive } \\
\text { strength } \\
(\mathrm{MPa})\end{array}$ & \\
\hline Mix 1 & 4.4 & 28.4 & 22.5 & 42.6 \\
\hline Mix 2 & 3.9 & 23.4 & 14.8 & 28.1 \\
\hline Mix 3 & 4.4 & 28.1 & 22.1 & 49.8 \\
\hline Mix 4 & 3.9 & 19.5 & 10.5 & 23.2 \\
\hline Mix 5 & 4.4 & 28.9 & 23.4 & 54.7 \\
\hline Mix 6 & 4.4 & 30.2 & 25.3 & 47.6 \\
\hline Mix 7 & 4.6 & 30.3 & 25.9 & 48.8 \\
\hline Mix 8 & 4.6 & 30.2 & 26.5 & 49.1 \\
\hline
\end{tabular}

Mixture No. 3 containing steel slag aggregate and silica fume obtained $16.9 \%$, while mixture No. 5 with silica fume had $28.4 \%$ higher compressive strength compared to the conventional mixture. This increase is mainly due to the interaction between the concrete ingredients and the silica fume. The concrete mix containing 10,20, and $30 \%$ steel slag aggregates showed an improved bond with the concrete ingredients, resulting $11.8,16.8$, and $17 \%$ higher compressive strength compared to reference mix, respectively.

\section{CONCLUSION}

The effects of using artificial fine aggregates (slag and glass waste) as a partial replacement of natural fine aggregate were investigated together with silica fume as a cement replacement on the fresh and hardened concrete. The following conclusions have been drawn from the experiments:

Compressive strength of concrete mixes containing glass waste of $10 \%$, with or without silica fume, measured on cube specimens by ultrasonic pulse velocity, rebound hammer and destructive tests achieved lower values compared to the concrete with the conventional mix. The lower strength is mainly attributed to weaker bond between the glass particles and the cement matrix with increased porosity.

Concrete mix with $10 \%$ silica fume measured by cement weight showed higher compressive strength than other concrete mix. The higher compressive strength is mainly due to the interaction between the particles of cement and the silica fume, which resulted in dense packing of particles and lower porosity. However, the long-term strength may be affected by the alkali-silica reaction, so this phenomenon would require further investigation.

Adding silica fume to the concrete mixtures leads to a decrease in workability. For more optimal performance further investigation would be needed to check chemical composition, shape, size, and the surface texture of the applied silica fume.

The steel slag applied up to $30 \%$ of the fine aggregate weight provided a better compressive strength compared to 
the conventional mixture can be used as a partial substituent of sand for concrete grade up to C30/37, as it was used to design whole concrete mix. The growth in compressive strength can be explained by a better bond between the steel slag aggregate and the cement matrix.

Test results confirmed that the use of steel slag aggregates and the silica fume can increase compressive strength of normal concrete and can successfully be used for the production of normal grade concrete glass waste is mainly recommended for lower grade concrete mixes.

\section{ACKNOWLEDGEMENT}

The research project is conducted at the University of Pécs, Hungary, within the framework of the Biomedical Engineering Project of the Thematic Excellence Programme 2019 (TUDFO/51757-1/2019-ITM).

\section{REFERENCES}

[1] R. K. Patra and B. B. Mukharjee, "Influence of incorporation of granulated blast furnace slag as a replacement of fine aggregate on properties of concrete", J. Clean. Prod., vol. 165, pp. 468-476, 2017.

[2] J. Liu, Q. Yu, Z. Zuo, F. Yang, Z. Han, and Q. Qin, "Reactivity and performance of dry granulation blast furnace slag cement", Cem. Concr. Composit., vol. 95, pp. 19-24, 2019.

[3] M. Maslehuddin, A. M. Sharif, M. Shameem, M. Ibrahim, and M. S. Barry, "Comparison of properties of steel slag and crushed limestone aggregate concretes", Constr. Build. Mater., vol. 17, no. 2, pp. 105-112, 2003.

[4] A. Shayan and A. Xu, "Value-added utilization of waste glass in concrete", Cem. Concre. Res., vol. 34, no. 1, pp. 81-89, 2004.

[5] A. Saand, A. K. Manthar, R. Juj, S. Khoso, and D. K. Bangwar, "Utilization of waste glass as partial replacement of fine aggregate in concrete”, Eng. Sci. Technol. Int. Res. J., vol. 1, no. 1, pp. 28-31, 2017.

[6] K. K. Sahoo, P. Sarkar, and R. Davis, "Mechanical properties of silica fume concrete designed as per construction practice", in Proceedings of Institution of Civil Engineers, Construction Materials, vol. 172, no. 1, pp. 20-28, 2019.

[7] J. Junak, N. Stevulova, and M. Ondova, "Concrete sample prepared with different types of waste", Pollack Perod., vol. 9, No. Supplement, pp. 95-104, 2014.

[8] M. Draganovska, A. Sicakova, and M. Holub, "Determination of the basic characteristics of sludge for utilization in building cement composities", Pollack Perod., vol. 4, no. Supplement, pp. 113-122, 2015.

[9] S. B. Park and M. Tia, "The effects of super-plasticizers on the engineering properties of plain concrete", Transport. Res. Rec., no. 1062, pp. 38-46, 1999.

[10] M. S. Mohammed, S. A. Mohamed, and M. A. M. Johari, "Influence of super-plasticizer compatibility on the setting time, strength, and stiffening characteristics of concrete", Adv. Appl. Sci., vol. 1, no. 2, pp. 30-36, 2016.

[11] EN 197-1:2011, Cement, Part 1: Composition, specifications and conformity criteria for common cements, CEN, Brussels, 2011.

[12] MSZ EN 933-1:1998, Test for geometrical properties of aggregates. Part 1: Determination of particle size distribution. Sieving method, CEN, Brussels, 1998.

[13] MSZ EN 1097-6:2013, Tests for mechanical and physical properties of aggregates. Part 6: Determination of particle density and water absorption, CEN, Brussels, 2013.

[14] EN 1992-1-1:2004, Eurocode 2: Design of concrete structures, Part 1-1-: General rules and rules for buildings, CEN, Brussels, 2004.

[15] EN 12350-2:2009, Testing of fresh concrete, Part 2: Slump test, CEN, Brussels, 2009.

[16] EN 12350-7:2009, Testing fresh concrete, air content, pressure methods, CEN, Brussels, 2009.

[17] EN 12350-6:2009, Testing fresh concrete, density, CEN, Brussels, 2009.

[18] EN 12390-7:2009, Testing hardened concrete, Part 7: Density of hardened concrete, CEN, Brussels, 2009.

[19] EN 12504-4:2005, Testing concrete, Part 4: Determination of ultrasonic pulse velocity, CEN, Brussels, 2005.

[20] EN 12390-3:2009, Testing hardened concrete, Part 3: Compressive strength of test specimens, CEN, Brussels, 2009.

[21] RILEM recommendations for the testing and use of constructions materials, Rilem, 1994. 